\title{
Energy Consumption Inequality and Human Development
}

\author{
Qiaosheng $\mathrm{Wu}^{1}$, Svetlana Maslyuk ${ }^{2}$ and Valerie Clulow ${ }^{3}$ \\ ${ }^{1}$ School of Economics and Management, China University of Geosciences, Wuhan \\ ${ }^{2}$ School of Business and Economics, Monash University, Victoria, \\ ${ }^{3}$ College of Business, RMIT University, Melbourne, \\ ${ }^{1}$ China \\ 2,3 Australia
}

\section{Introduction}

Empirical evidence shows that growing energy consumption leads to a rapid increase in global greenhouse gases emissions (henceforth GHG). As the largest market failure ever experienced, diffusion of GHG in the global atmosphere happens quickly, regardless ofwhere the GHG is emitted (Sinn, 2007). Evidently, by century's end, energy-related carbon dioxide emissions would, at current rates, more than double, putting the world onto a potentially catastrophic trajectory, which could lead to warming of $5^{\circ} \mathrm{C}$ or more compared with preindustrial times (IEA, 2009). The existing energy system with most of the energy consumed by the developed nations, has underpinned and constructed deeply unequal social relations, as well as imbalanced nature-society relations. At present given current resource constraints, developing nations cannot follow the path previously chosen by the developed nations to achieve economic growth.

Following Jacobson et al. (2005), the distribution of and access to energy resources may result in significant social, environmental and economic inequalities. To date, inequality in energy consumption across countries has received very limited analytical attention. In the recent literature devoted to climate change, there have been several attempts to use the tools of conventional income distribution analysis to measure inequality in carbon dioxide $\left(\mathrm{CO}_{2}\right)$ emissions across countries and changes in inequality over time (see Heil \& Wodon, 1997, 2000; Hedenus \& Azar, 2005; Duro \& Padilla, 2006; Padilla \& Serrana, 2006; Groot, 2010). Yet, very few studies in the energy literature apart from Jacmart et al. (1979), Jaconson et al. (2005) and Rosas-Flores et al. (2010) have analysed inequality in energy consumption for a large sample of countries.

One of the first to notice the correlation between per capita energy consumption, standard of living and the degree of a country's development and to use the Lorenz curve to measure energy consumption inequality for 1950, 1969 and 1975 was Jacmart et al. (1979). They proposed that changes in the distribution of energy among countries provides another measure of trends in world's inequality and reported a decline in energy consumption inequality over time. In the analysis of the distribution of residential energy consumption in Norway, USA, El Salvador, Thailand and Kenya, Jacobson et al. (2005) found dramatic 
differences between energy use of developed and developing nations with Kenya, El Salvador and Thailand having the highest inequality in energy consumption respectively. These differences can be explained by the differences in a nation's wealth, income distribution and government infrastructure as well as climatic conditions, energy efficiency measures and size and geographic distribution of the rural population. In the analysis of inequality in the distribution of expenses associated with main energy fuels in Mexico, Rosas-Flores et al. (2010) found that natural gas, electricity and gasoline were consumed mainly by the higher income earners, while firewood and kerosene were the main fuels for the lower income consumers.

In the past, the improvements in the human quality of life meant greater use of energy, however it is no longer possible under the current supply contraints and climate change conditions. In fact the literature shows that good quality of life can be achieved on much lower energy consumption levels (Pasternak, 2000, Pachari and Spreng, 2003, Spreng, 2005). According to the United Nations (UN) 2007/2008 Human Development Report, under the energy supply constraints and the constant necessity to improve energy efficiency, when energy use is associated with human development, it is possible to find opportunities for the synergetic development of energy and society, by shifting the focus of the economy to satisfying basic human needs. It is possible to introduce a sufficientarian 'development threshold' attributed to global energy consumption, by the use of the nationally-weighted human development indicators such as the United Nations Development Program (UNDP) Human Development Index (HDI).

The purpose of the study reported in this chapter, is to measure energy consumption inequality by using the standard tools of economic analysis - the Lorenz curve and Gini coefficient. These inequality measures also provide critical insights into the temporal evolution of energy management in different states and nations, and allow us to visualise the impact of factors such as new technologies, government policies, etc (Jacobson et al., 2005). In this chapter, four Lorenz curves were generated based on the four equity criterions namely production-based, energy consumption-based, human development and economic activity equity criterions.

The list of 129 countreis analyzed in this study is given in Table 1 below. To calculate energy consumption inequality measures we use UNDP HDI and the International Energy Agency (IEA) data on per capita energy consumption. HDI is composed of three elements including longevity (L), as proxied by the life expectancy at birth, education index (E, a combination of adult literacy and gross enrollment indeces) and income as measured by the GDP per capita PPP USD index. Because they are equally important, HDI components are weighted equally. The following equations represent how the HDI components are calculated:

$$
\begin{gathered}
L=\frac{\text { Life Expectancy }-25}{85-25} \\
E=\frac{2}{3} * \text { Adult Literacy Index }+\frac{1}{3} * \text { Gross Enrollment Index } \\
G D P=\frac{\log (\text { GDP per capita })-\log (100)}{\log (40000)-\log (100)}
\end{gathered}
$$

The 2009 UNDP Human Development Report divided nations into three groups based on their HDI level. High human development economies (HHD) have HDI $\geq 0.85$, medium 


\begin{tabular}{|c|c|c|c|c|c|}
\hline Country & $\begin{array}{l}\text { HD } \\
\text { Category }\end{array}$ & Country & $\begin{array}{l}\text { HD } \\
\text { Category }\end{array}$ & Country & $\begin{array}{l}\text { HD } \\
\text { Category }\end{array}$ \\
\hline Albania & $\mathrm{M}$ & Gabon & $\mathrm{M}$ & Nigeria & $\mathrm{L}$ \\
\hline Algeria & M & Georgia & M & Norway & $\mathrm{H}$ \\
\hline Angola & $\mathrm{L}$ & Germany & $\mathrm{H}$ & Oman & M \\
\hline Argentina & $\mathrm{H}$ & Ghana & $\mathrm{L}$ & Pakistan & $\mathrm{L}$ \\
\hline Armenia & $\mathrm{M}$ & Greece & $\mathrm{H}$ & Panama & $\mathrm{M}$ \\
\hline Australia & $\mathrm{H}$ & Guatemala & M & Paraguay & $\mathrm{M}$ \\
\hline Austria & $\mathrm{H}$ & Haiti & $\mathrm{L}$ & Peru & $\mathrm{M}$ \\
\hline Azerbaijan & M & Honduras & M & Philippines & $\mathrm{M}$ \\
\hline Bahrain & $\mathrm{H}$ & Hungary & $\mathrm{H}$ & Poland & $\mathrm{H}$ \\
\hline Bangladesh & $\mathrm{L}$ & Iceland & $\mathrm{H}$ & Portugal & $\mathrm{H}$ \\
\hline Belarus & $\mathrm{M}$ & India & M & Qatar & $\mathrm{H}$ \\
\hline Belgium & $\mathrm{H}$ & Indonesia & M & Romania & M \\
\hline Benin & $\mathrm{L}$ & Iran & $\mathrm{M}$ & $\begin{array}{l}\text { Russian } \\
\text { Federation }\end{array}$ & $\mathrm{M}$ \\
\hline Bolivia & M & Ireland & $\mathrm{H}$ & Saudi Arabia & M \\
\hline Bosnia and Herzegovina & M & Israel & $\mathrm{H}$ & Senegal & $\mathrm{L}$ \\
\hline Botswana & $\mathrm{M}$ & Italy & $\mathrm{H}$ & Singapore & $\mathrm{H}$ \\
\hline Brazil & M & Jamaica & M & Slovakia & $\mathrm{H}$ \\
\hline Brunei Darussalam & $\mathrm{H}$ & Japan & $\mathrm{H}$ & Slovenia & $\mathrm{H}$ \\
\hline Bulgaria & $\mathrm{M}$ & Jordan & M & South Africa & $\mathrm{M}$ \\
\hline Cambodia & M & Kazakhstan & M & Spain & $\mathrm{H}$ \\
\hline Cameroon & $\mathrm{L}$ & Kenya & $\mathrm{L}$ & Sri Lanka & M \\
\hline Canada & $\mathrm{H}$ & Korea & $\mathrm{H}$ & Sudan & $\mathrm{L}$ \\
\hline Chile & $\mathrm{H}$ & Kuwait & $\mathrm{H}$ & Sweden & $\mathrm{H}$ \\
\hline China & M & Kyrgyzstan & M & Switzerland & $\mathrm{H}$ \\
\hline Colombia & $\mathrm{M}$ & Latvia & $\mathrm{H}$ & $\begin{array}{l}\text { Syrian Arab } \\
\text { Republic }\end{array}$ & M \\
\hline Congo & $\mathrm{L}$ & Lebanon & M & Tajikistan & M \\
\hline $\begin{array}{l}\text { Congo(Democratic } \\
\text { Republic ) }\end{array}$ & $\mathrm{L}$ & $\begin{array}{l}\text { Libyan Arab } \\
\text { Jamahiriya }\end{array}$ & $\mathrm{M}$ & Tanzania & $\mathrm{L}$ \\
\hline Costa Rica & $\mathrm{H}$ & Lithuania & $\mathrm{H}$ & Thailand & M \\
\hline Côte d'Ivoire & $\mathrm{L}$ & Luxembourg & $\mathrm{H}$ & Togo & $\mathrm{L}$ \\
\hline Croatia & $\mathrm{H}$ & Macedonia & M & $\begin{array}{l}\text { Trinidad and } \\
\text { Tobago }\end{array}$ & M \\
\hline Cuba & $\mathrm{H}$ & Malaysia & M & Tunisia & M \\
\hline Cyprus & $\mathrm{H}$ & Malta & $\mathrm{H}$ & Turkey & $\mathrm{M}$ \\
\hline Czech Republic & $\mathrm{H}$ & Mexico & $\mathrm{M}$ & Turkmenistan & $\mathrm{M}$ \\
\hline Denmark & $\mathrm{H}$ & Moldova & M & Ukraine & M \\
\hline Dominican Republic & M & Mongolia & M & $\begin{array}{l}\text { United Arab } \\
\text { Emirates }\end{array}$ & $\mathrm{H}$ \\
\hline Ecuador & M & Morocco & M & United Kingdom & $\mathrm{H}$ \\
\hline Egypt & M & Mozambique & $\mathrm{L}$ & United States & $\mathrm{H}$ \\
\hline El Salvador & M & Myanmar & M & Uruguay & $\mathrm{H}$ \\
\hline Eritrea & $\mathrm{L}$ & Namibia & M & Uzbekistan & $\mathrm{M}$ \\
\hline Estonia & $\mathrm{H}$ & Nepal & $\mathrm{L}$ & Venezuela & M \\
\hline Ethiopia & $\mathrm{L}$ & Netherlands & $\mathrm{H}$ & Viet Nam & M \\
\hline Finland & $\mathrm{H}$ & New Zealand & $\mathrm{H}$ & Yemen & $\mathrm{L}$ \\
\hline France & $\mathrm{H}$ & Nicaragua & M & Zambia & $\mathrm{L}$ \\
\hline
\end{tabular}

Note: The grouping of the countries is based by the 2009 UNDP Human Development Report. H-high human development countries, M --medium human development countries, L --low human development countries.

Table 1. Countries included in the sample. 
human development economies (MHD) have $0.6 \leq \mathrm{HDI}<0.85$ and low human development economies (LHD) have HDI <0.6. In 2007, 47 economies corresponded to HHD, 60 to MHD and 22 to LHD nations respectively. The period 1998 to 2007 was chosen for this analysis because it corresponds to comparable metgodology of the HDI calculation used by the UNDP allowing us to compare the inequality measures across a common time period.

Table 2 contains total primary energy supply (TPES) per capita, GDP, population and HDI values for 30 countries with the largest per capita energy consumption in the world.

\begin{tabular}{|c|c|c|c|c|c|c|c|}
\hline Country & $\begin{array}{l}\text { TPES/pop, } \\
\text { toe/capita }\end{array}$ & $\begin{array}{c}\text { GDP, } \\
\text { Billion } \\
\text { 2000\$,PPP }\end{array}$ & $\begin{array}{l}\% \text { of World } \\
\text { total GDP }\end{array}$ & $\begin{array}{l}\text { GDP/pop, } \\
2000 \$ / \text { capita, } \\
\text { PPP }\end{array}$ & $\begin{array}{l}\text { Population, } \\
\text { Million }\end{array}$ & $\begin{array}{l}\% \text { of World total } \\
\text { population }\end{array}$ & HDI \\
\hline Qatar & 26.5392 & 29.02 & 0.047 & 34548 & 0.84 & 0.013 & 0.901 \\
\hline Iceland & 15.7377 & 10.83 & 0.018 & 34935 & 0.31 & 0.005 & 0.968 \\
\hline $\begin{array}{l}\text { United Arab } \\
\text { Emirates }\end{array}$ & 11.8296 & 113.85 & 0.185 & 26053 & 4.37 & 0.066 & 0.879 \\
\hline Bahrain & 11.6523 & 16.12 & 0.026 & 21493 & 0.75 & 0.011 & 0.878 \\
\hline $\begin{array}{l}\text { Trinidad and } \\
\text { Tobago }\end{array}$ & 11.4646 & 20.35 & 0.033 & 15301 & 1.33 & 0.02 & 0.813 \\
\hline Kuwait & 9.4631 & 70.73 & 0.115 & 26590 & 2.66 & 0.04 & 0.893 \\
\hline Luxembourg & 8.7901 & 31.2 & 0.051 & 65000 & 0.48 & 0.007 & 0.96 \\
\hline Canada & 8.1686 & 1046.87 & 1.704 & 31743 & 32.98 & 0.499 & 0.959 \\
\hline United States & 7.7459 & 11468 & 18.669 & 37962 & 302.09 & 4.571 & 0.953 \\
\hline $\begin{array}{l}\text { Brunei } \\
\text { Darussalam }\end{array}$ & 7.114 & 6.03 & 0.01 & 15462 & 0.39 & 0.006 & 0.866 \\
\hline Finland & 6.8962 & 164.81 & 0.268 & 31155 & 5.29 & 0.08 & 0.953 \\
\hline Saudi Arabia & 6.2128 & 360.74 & 0.587 & 14907 & 24.2 & 0.366 & 0.819 \\
\hline Oman & 5.9536 & 44.73 & 0.073 & 17204 & 2.6 & 0.039 & 0.83 \\
\hline Australia & 5.8703 & 666.78 & 1.085 & 31541 & 21.14 & 0.32 & 0.965 \\
\hline Singapore & 5.83 & 135.88 & 0.221 & 29603 & 4.59 & 0.069 & 0.928 \\
\hline Norway & 5.7075 & 190.75 & 0.311 & 40499 & 4.71 & 0.071 & 0.971 \\
\hline Sweden & 5.5118 & 298.31 & 0.486 & 32602 & 9.15 & 0.138 & 0.957 \\
\hline Belgium & 5.3683 & 323.58 & 0.527 & 30469 & 10.62 & 0.161 & 0.946 \\
\hline Netherlands & 4.9107 & 534.06 & 0.869 & 32604 & 16.38 & 0.248 & 0.955 \\
\hline $\begin{array}{l}\text { Russian } \\
\text { Federation }\end{array}$ & 4.7455 & 1603.73 & 2.611 & 11323 & 141.64 & 2.143 & 0.803 \\
\hline Korea & 4.5855 & 1065.75 & 1.735 & 21992 & 48.46 & 0.733 & 0.931 \\
\hline Czech Republic & 4.4324 & 209.12 & 0.34 & 20264 & 10.32 & 0.156 & 0.893 \\
\hline Kazakhstan & 4.2931 & 127.68 & 0.208 & 8248 & 15.48 & 0.234 & 0.788 \\
\hline Estonia & 4.1972 & 22.03 & 0.036 & 16440 & 1.34 & 0.02 & 0.872 \\
\hline France & 4.1483 & 1737.96 & 2.829 & 27339 & 63.57 & 0.962 & 0.949 \\
\hline Germany & 4.0268 & 2315.34 & 3.769 & 28147 & 82.26 & 1.245 & 0.936 \\
\hline Japan & 4.0195 & 3620.16 & 5.893 & 28336 & 127.76 & 1.933 & 0.951 \\
\hline New Zealand & 4.0075 & 101.07 & 0.165 & 24122 & 4.19 & 0.063 & 0.942 \\
\hline Austria & 3.99 & 266.51 & 0.434 & 32032 & 8.32 & 0.126 & 0.946 \\
\hline Turkmenistan & 3.6416 & 38.18 & 0.062 & 7698 & 4.96 & 0.075 & 0.764 \\
\hline Other countries & 1.154 & 34787.8 & 56.6 & 6150 & 5656.1 & 85.6 & - \\
\hline World & 1.82 & 61428.02 & 100 & 9294 & 6609.27 & 100 & - \\
\hline
\end{tabular}

Table 2. Top 30 energy consumers. 
Although the majority of these nations are developed economies, the list also contains resource-rich developing nations such as Qatar and Oman. The United States with high human development level (HDI is 0.953 in 2007) was the largest energy consumer in the world, consuming 20 percent of the world's total energy. Other nations with relatively high levels of energy use are Qatar, Iceland, United Arab Emirates, Bahrain, Trinidad and Tobago, Kuwait, Luxembourg and Canada. Norway has the highest human development level due to the highest HDI value.

In this study we found that inequality of energy consumption has been decreasing over the entire time period of analysis. This can be attributed to several factors including globalization and improved access to energy and infrastructure in some developed countries (e.g. China and India). We suggest that concerns to do with inequality of energy consumption must be incorporated and integrated into the development strategies for all countries irrespective of their human development level.

The chapter is structured as follows. Section 2 describes inequality measures used in this chapter. Section 3 discusses energy consumption inequality using four equaity criteria. Section 4 provides an overview of inequality in time from 1998 to 2007 and Section 5 concludes the chapter by analysing policy implications of our findings.

\section{Measuring energy consumption inequality}

In order to visualize HHD-MHD/-LHD energy consumption inequality between countries this chapter uses the Lorenz curve and the Gini coefficient. In traditional economics, the Lorenz curve shows what percentage of the total income is held by the corresponding percentage of households, where households are ranked by level of income. Applying the Lorenz curve in the context of energy consumption, means replacing households by countries, and ranking by income is replaced by ranking by energy consumption per capita across countries. Doing so results in a Lorenz curve that depicts distribution of cumulative percentage of world population on the abscissa axis versus the cumulative percentage of the energy consumption distributed along the ordinate axis.

Mathematically Lorenz curve can be represented as

$$
y=f(p),
$$

where $p$ is the cumulative population share of persons earning income equal to or below income level $x, y$ is the cumulative income share of population subgroup $p$. Any Lorenz curve must have the following properties,

$$
\frac{d y}{d p}>0, \frac{d^{2} y}{d p^{2}}>0, y(0)=0, y(1)=1,
$$

and is defined on the domain $0 \leq p \leq 1$.

Applying the Lorenz curve in the context of energy consumption, means replacing households by countries, and ranking by income is replaced by ranking by energy consumption per capita across countries. Doing so results in a Lorenz curve that depicts 
distribution of cumulative percentage of world population on the abscissa axis versus the cumulative percentage of the energy consumption distributed along the ordinate axis (Jacobson et al., 2005). In fact, the criterion to rank countries is fully determined by the variables used on the coordinate axes in a Lorenz diagram (Groot, 2010). Therefore, one can also construct a Lorenz curve where the horizontal axis measures cumulative world GDP shares instead of cumulative world population shares (Groot, 2010).

Figure 1 shows an energy consumption Lorenz curve in 2007 for countries sorted by per capita GDP PPP. The 45 degree line represents the line of perfect equality, where national energy consumption is equalized globally on a per capita basis. The area between the perfect equity line and the actual distribution (Lorenz) curve is given by the Gini coefficient wich is calculated as

$$
\text { Gini }=\sum_{i=0}^{n} \frac{100^{2}-\left[\left(P_{i+1}-P_{i}\right)\left(E_{i}+E_{i+1}\right)\right]}{100^{2}},
$$

where $P_{i}$ is the population share of country $i$ and $E_{i}$ is its energy consumption share in world population and in total world energy consumption respectively. In this case the Gini coefficient indicates the degree of global inequality in per capita energy consumption. A Gini coefficient of zero corresponds to perfect equality in per capita energy consumption among all countries in the sample (every country consumes the same amount of energy and the Lorenz curve corresponds to the 45-degree line), while a Gini coefficient of one would indicate perfect inequality in energy consumption, arising due to all the world's energy being consumed by one nation. For the year 2007, Gini coefficient corresponding to Lorenz curve shown on Figure 1 is 0.47, implying that distribution of energy consumption in 2007 between the richest and the poorest nations that was not equal.
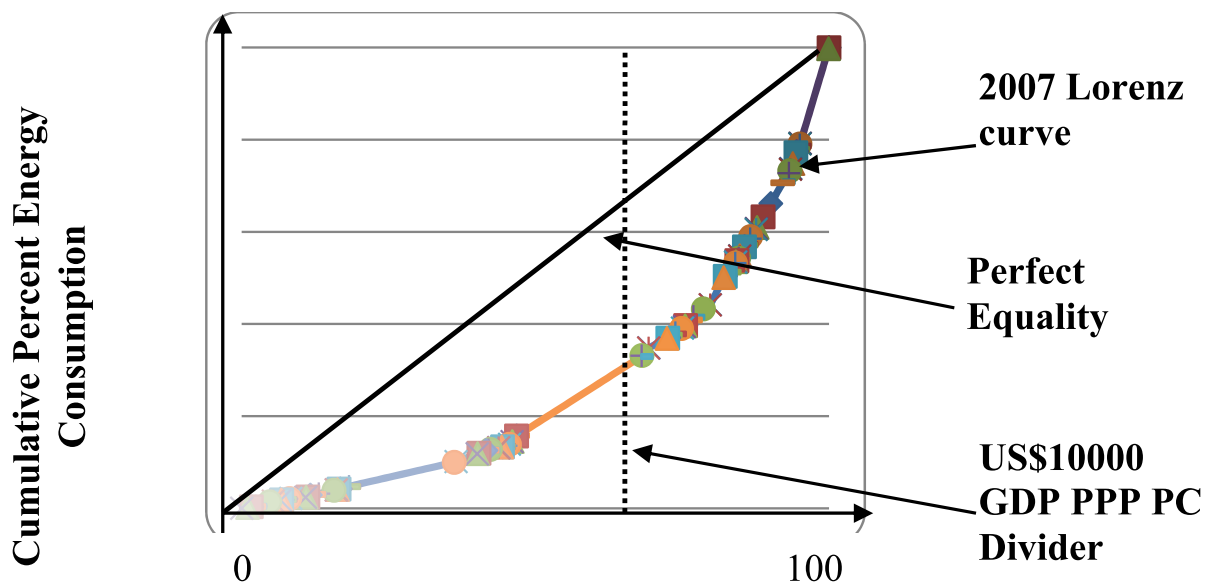

\section{Cumulative World GDP Shares (\%)}

Fig. 1. The Lorenz curve for energy consumption in 2007 for countries sorted by per capita GDP PPP. 
A potentially more intuitive way to interpret Figure 1 is by using GDP of US\$ 10000 PPP as a divider between lower and higher income countries. Then, in 2007, 75\% of the world's population with per capita GDP of less than US $\$ 10000$ accounted for $40 \%$ of global energy consumption. The remaining $25 \%$ of population with GDP PPP per capita of more than US $\$ 10000$ accounted for $60 \%$ of global energy consumption.

\section{Energy consumption inequality criterions}

By ranking countries in a different way it is possible to construct a different Lorenz curve, and it will be shown that the criterion to rank countries is fully determined by the variables used on the coordinate axes in a Lorenz diagram (Groot, 2010). In this chapter we generate four Lorenz curves based on four equity criterions. The first is an energy consumptionbased equity criterion which is predicated on the rationale that all countries should have an equal right to use energy for its social and economic development. In this case the Lorenz curve is constructed by plotting per capita energy consumption shares in the cumulative world energy consumption on the vertical axis, and cumulative world population shares (\%) on the horizontal axis. Second is an energy production-based sovereignity equity criterion which is connected to a country's capabilities to produce and consume its own energy. In this case, the horizontal axis of the Lorenz curve is found by sorting cumulative world population shares (\%) by per capita energy production. Third is an economic activity equity criterion. In this study we use energy intensity or the number of energy units used in the production of a nation's GDP as the proxy for economic activity. High/low energy intensity represents high/low cost of converting energy into GDP. The Lorenz curve is sorted by energy intensity, where cumulative world GDP shares (\%) ranked by energy intensity is on the horizontal and cumulative world energy consumption shares (\%) are on the vertical axes. Last is a human development equity criterion which is based on the HDI. In this case cumulative world energy consumption shares (\%) are on the vertical axis and cumulative world population shares (\%) ranked by the HDI are on the horizontal axis. According to the conventional welfare theories, to achieve higher human development, each individual should enjoy development rights, including social, economic, political, as well as the basic survival needs and the provision of non-material services based upon demand for natural resources. Therefore, the concept of human development is important because it is not only concerned with the current state of the human well-being but also with the realization of human potential. This criterion implies that each member of the society is entitled to realize their basic human right to development potential given constrained natural resources.

Figure 2 shows the distribution of 2007 energy consumption under energy consumption-based equity criterion. Based on this criteria, the Gini coefficient was 0.50 . Top 10 countries in terms of energy cosumption include: Qatar, Iceland, United Arab Emirates, Bahrain, Trinidad and Tobago, Kuwait, Luxembourg, Canada, United States and Brunei Darussalam. These countries harbour $5.52 \%$ of the world's population, and use $24.06 \%$ of the world's energy.

Figure 3 shows the distribution of 2007 energy consumption under energy production equity criterion. In 2007 the Gini coefficient was 0.39 . Per capita energy production in the top 10 countries include: Qatar, Kuwait, Brunei Darussalam, Norway, United Arab Emirates, Trinidad and Tobago, Oman, Saudi Arabia, Bahrain and Libyan Arab Jamahiriya. These nations harbor $0.77 \%$ of the population, and produce $12.23 \%$ of the world's energy, but consume $2.95 \%$ of the world's energy. 


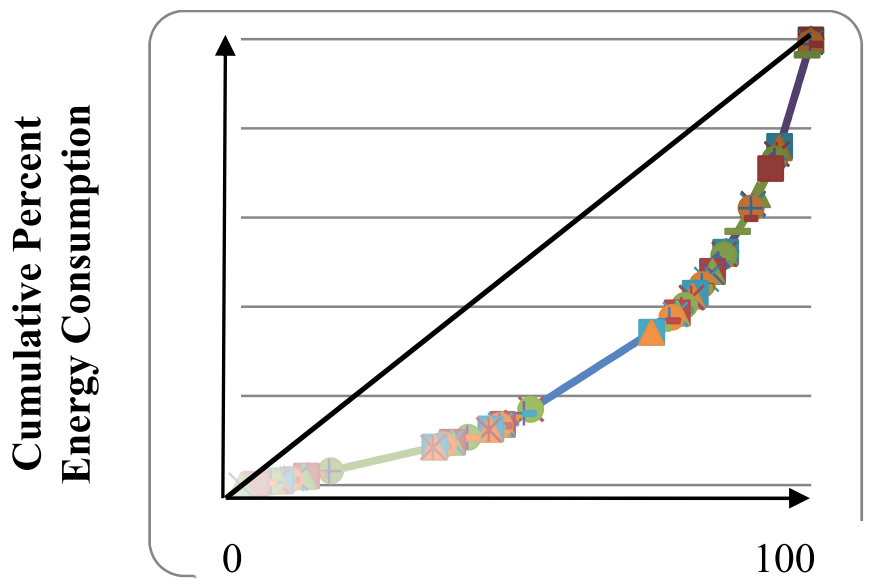

Cumulative Population (\%)

Fig. 2. The Lorenz curve in 2007 for countries sorted by per capita energy consumption.

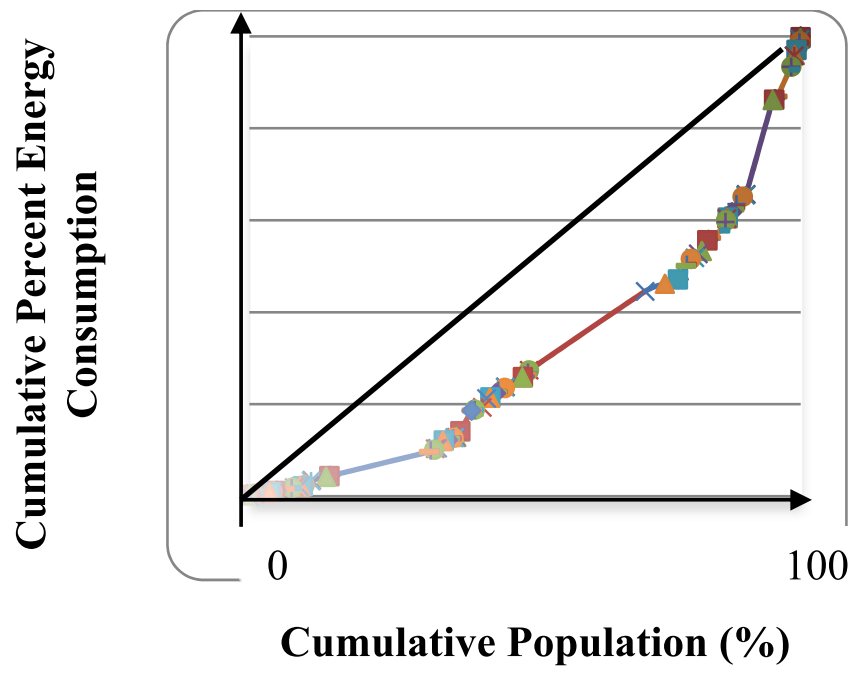

Fig. 3. The Lorenz curve in 2007 for countries sorted by per capita energy production.

Figure 4 shows the distribution of 2007 energy consumption under economic activity equity criterion. In 2007 the Gini coefficient was 0.19 . The energy intensity of the top 10 countries namely, Uzbekistan, Qatar, Trinidad and Tobago, Nigeria, Tanzania, Zambia, Bahrain, Kazakhstan, Jamaica and Tajikistan, with GDP of $0.78 \%$ of the 129 countries, indicateduse of $2.65 \%$ of world's energy. 


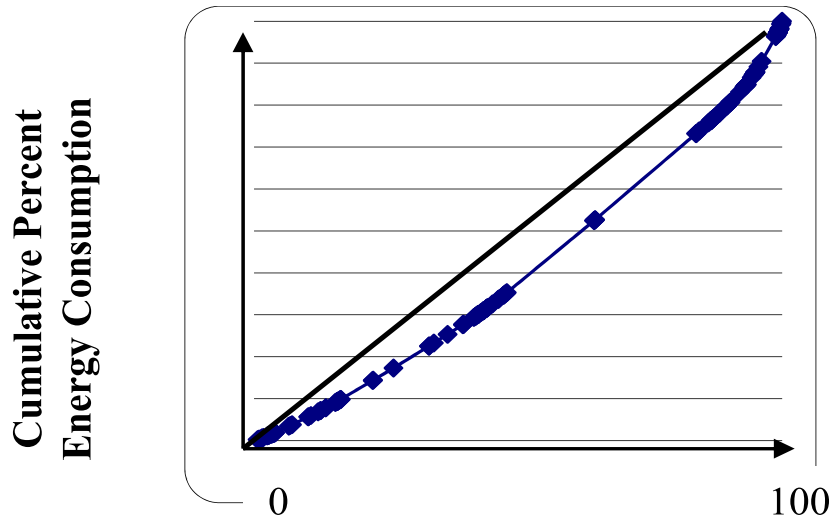

Cumulative Per cent GDP

Fig. 4. The Lorenz curve in 2007 for countries sorted by energy intensity.

Figure 5 shows the Lorenz curve sorted by HDI criterion, where cumulative world energy consumption shares (\%) are on the vertical axis and cumulative world population shares (\%) are on the horizontal axis. The Gini coefficient in 2007 is 0.46. Top 10 HDI nations are Norway, Iceland, Australia, Ireland, Luxembourg, Canada, Sweden,the Netherlands, Finland, United States. Their total GDP accounts for $23.7 \%$ of the world's GDP, $6.3 \%$ of the world's population, and use $25.9 \%$ of the world's energy. The energy use of HHD countries is $48.5 \%$ of the world's total, their GDP accounts for $52.3 \%$ of the world's total, and they are the home countries of $17.8 \%$ of the world's population. MHD countries use $48.1 \%$ of the world's energy, harbor $67.3 \%$ of the world's population and account for $43.1 \%$ of the world's GDP. LHD countries harbor $14.9 \%$ of the world's population and only use $3.4 \%$ of the world's energy.

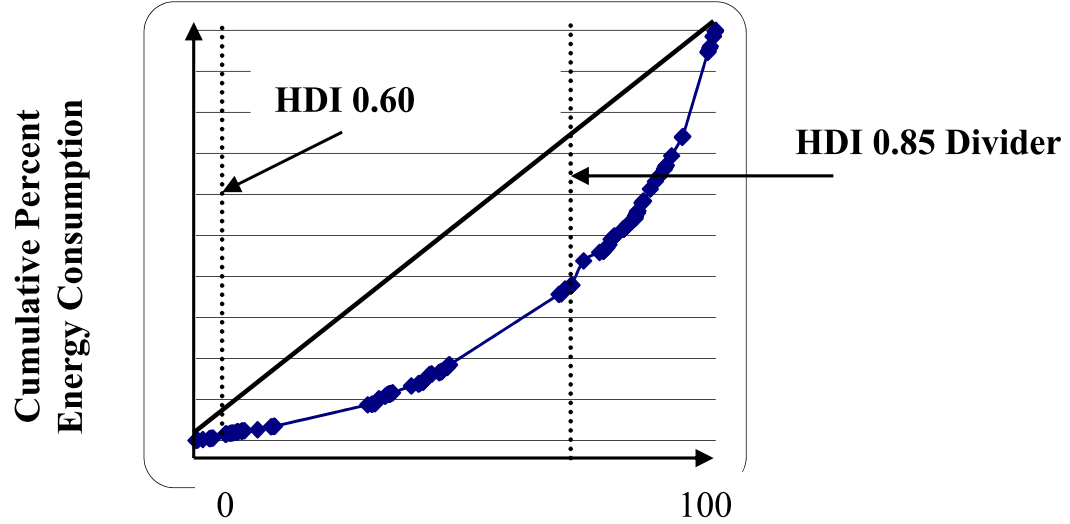

Cumulative Population (\%)

Fig. 5. The Lorenz curve in 2007 for countries sorted by HDI. 


\section{Energy consumption inequality from 1998 to 2007}

Table 3 and Figure 6 present calculated Gini coefficients calculated based on the four equity criterions from 1998 to 2007. One can see that although inequality in energy consumption (shown by the difference between the respective Lorenz curve and the diagonal and decline in the Gini coefficient values) has diminished over the time according to all four criterions analysed, it did not disappear completely.

\begin{tabular}{ccccc}
\hline Year & \multicolumn{5}{c}{ Gini coefficient } \\
\cline { 2 - 5 } & $\begin{array}{c}\text { Energy production- } \\
\text { based criterion }\end{array}$ & $\begin{array}{c}\text { Energy consumption- } \\
\text { based criterion }\end{array}$ & $\begin{array}{c}\text { HDI } \\
\text { criterion }\end{array}$ & $\begin{array}{c}\text { Economic activity } \\
\text { criterion }\end{array}$ \\
\hline 1998 & 0.4273 & 0.5365 & 0.5052 & 0.2082 \\
1999 & 0.4237 & 0.5356 & 0.5013 & 0.2025 \\
2000 & 0.4262 & 0.5384 & 0.5059 & 0.2018 \\
2001 & 0.4240 & 0.5364 & 0.4956 & 0.1990 \\
2002 & 0.4206 & 0.5323 & 0.4965 & 0.1971 \\
2003 & 0.4129 & 0.5258 & 0.4876 & 0.1939 \\
2004 & 0.4043 & 0.5172 & 0.4781 & 0.1899 \\
2005 & 0.3996 & 0.5125 & 0.4746 & 0.1882 \\
2006 & 0.3951 & 0.5054 & 0.4656 & 0.1876 \\
2007 & 0.3890 & 0.5000 & 0.4572 & 0.1870 \\
\hline
\end{tabular}

Source: Authors' own calculations based on the UNDP (2000-2009) and IEA (2009).

Table 3. The Gini based on equity criterions from 1998 to 2007.

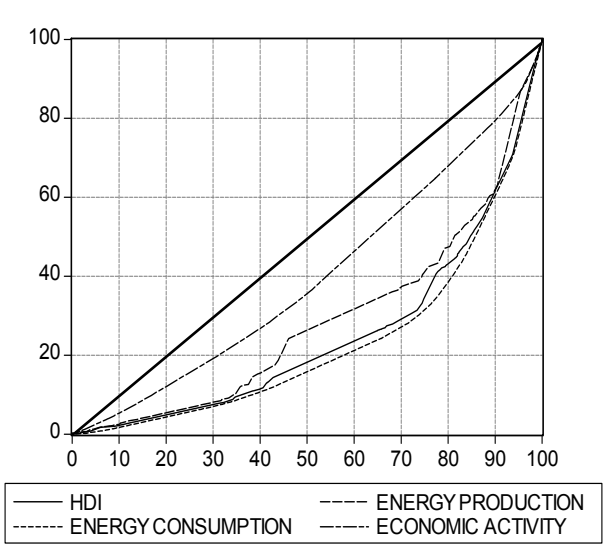

1998

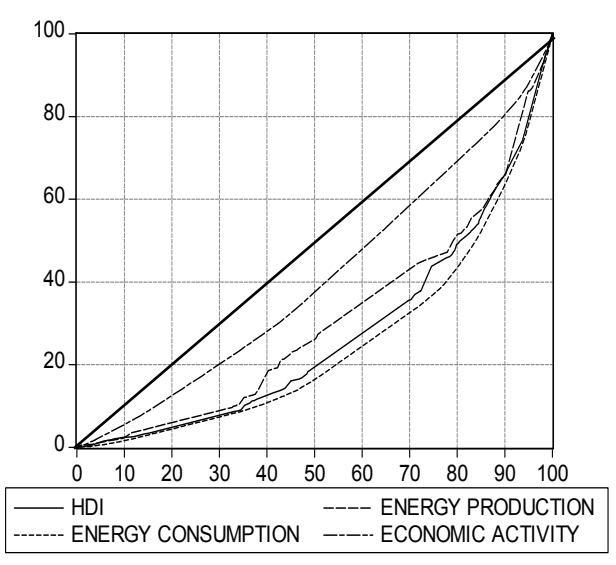

2007

Note: HDI - Human development equality criterion, ENERGY PRODUCTION - Energy productionbased equality criterion, ENERGY CONSUMPTION - Energy consumption-based equality criterion, ECONOMIC ACTIVITY - Economic activity equality criterion.

Fig. 6. The Lorenz curve in 1998 and 2007 for different equality criterions. 
One can see that the largest inequality is based on the HDI and energy consumption criterions. This finding can be explained by the continued poor access to energy resources by the developing nations, insufficient and in some cases inadequate infrastructure facilities and the use of energy-inefficient technologies. Although over the time, developed nations have improved access to energy resources, on average they are still consuming much less energy on a per capita basis as compared to the developed nations.

\section{Conclusion}

The distribution of energy resources may result in significant social, environmental and economic inequalities (Jacobson et al., 2005). A critical issue faced by policy makers across the world is how to distribute the costs and benefits through policies designed to address such problems. This chapter argues that energy consumption has a distinct and critical social dimension. Based on the UN Human Development Index, it analyses the energy consumption equality problem involving the different HDI groups. Although energy consumption inequality has been declining over time, it is not yet on a dissapearing trend. Economic growth, as well other socio-economic factors such as urbanisation and population increases are unbalanced globally, meaning that the contributions of developed and developing countries to climate change are changing. Therefore, compared with developed countries (which typically have high levels of energy consumption and corresponding high HDI and are aiming to keep a high standard of living), developing countries (usually they have lower HDI) have different tasks concerning energy consumption and human development. If the goal of low and medium HDI nation is to achieve improvement in its HDI, the goal of the high HDI nation is its maintenance.

In this study, we consider world energy consumption inequality from 1998 to 2007 and found that all of the conventional income inequality approaches can also be applied to the distribution of per capita energy consumption provided appropriate adjustments are made. We have chosen to apply the Lorenz curve and Gini coefficient to examine the inequality of per capita energy consumption across countries under different equality criteria. As stated earlier 1998 to 2007 was chosen as a sample period because it corresponded to the same methodology of HDI calculation used by the UNDP. In 2010 the UNDP has changed the HDI calculation methodology and approach to country classification. Therefore the calculation of inequality measures based on the new HDI definition is left to the future, but these measures will not be strictly comparable with the past.

Energy consumption inequality, as measured by the divergence of Lorenz curve from the diagonal and by the Gini coefficient, was found to be different based on different equity criterions. In particular, Gini coefficient was much lower when energy consumption shares are pictured against world GDP shares rather than world population shares. Irrespective of the equity criterion used, energy consumption inequality was found to be diminishing over time. These are the reasons that could have lead to a reduction in energy consumption inequality:

a. Globalization or the international integration of markets for goods, services and capital (Brune and Garrett, 2005). Globalization for developing countries often leads to an increase in the energy consumption as developed countries shift production and technologies to developing countries. 
b. Creation of essential infrastructure and establishing access to electricity in developing countries. In 2009 the number of people without access to electricity was 1.3 billion or almost $20 \%$ of the world's population (IEA, 2011). The speed of electrification in developing countries is still relatively slow, but it is happaning.

c. Changes in the energy consumption mix towards more efficient energy use and a shift towards alternative energy in developed countries and some developing. For example, in 2009 more than $84 \%$ of energy produced in Brazil was due to alternative energy sources, the largest of which was sugar cane ethanol. Although the shift towards alternative energy resources is still in the introductory stages, there is a lot of research underway in terms of solar energy, algae and wave energy. At the same time, technology for some energy sources, such as direct geothermal, has been already established.

d. Introduction of the climate change mitigation policies in both developed and developing nations in order to prevent dangerous anthropogenic interference with the climate system. Such policies target reduction in GHG gases, which can be achieved due to a reduction in energy consumption and more efficient energy use. Examples of such policies are carbon taxes and emissions trading schemes (ETS). While ETS are more recent instrument (e.g. ETS to control GHG in European Union have been operational since 2005), carbon taxes have been used since 1990s. ETS have been proposed to be introduced in Australia, Japan, US, Canada, Korea, India and China in the near future.

Figure 7 below shows that relationship between the HDI and energy consumption per capita (in tonnes of oil equivalent) is not linear. This means that at low human development levels, increase in energy consumption will lead to large increases in a country's HDI. This is supported by Martinez and Ebenhack (2008), who calculated that addition of $400 \mathrm{~kg}$ of oilequivalent per capita in the poorest nations with HDI values less than 0.4 will support a doubling of their HDI. However, as a country develops, the importance of energy in establishing higher HDI diminishes. Therefore for high and medium human development levels, simply increasing energy consumption is not enough to maintain its human development progress. In this case, a combination of factors such as more efficient energy use, development of energy-saving technologies, establishing appropriate social welfare systems and others are necessary to achieve and maintain high HDI.

Maintenance of high HDI would require policies targeting efficient energy use both on personal and company-based level and promoting energy-efficient technologies. Such policies should be country-specific and reflect current energy mix, industrial structure, potential fossill fuel and alternative energy resources, exisiting climate change mitigation policies (e.g. environmental taxes, subsidies for clean energy initiatives, creating a market for pollution, etc) and global action in climate change mitigation. For example, Canada and Germany are the world leaders in terms of direct geothermal energy and solar power respectively.

At the same time, low HDI countries should reduce energy poverty by creating essential infrastrure, changing their energy consumption mix and establishing access to modern energy sources. For instance, low HDI nations such as Nairobi and Gabon are largely dependent on biomass (firewood, charcoal or dung) as the primary energy source, which is not efficient energy source and highly GHG pollusive. Effors targeting establishing access to 


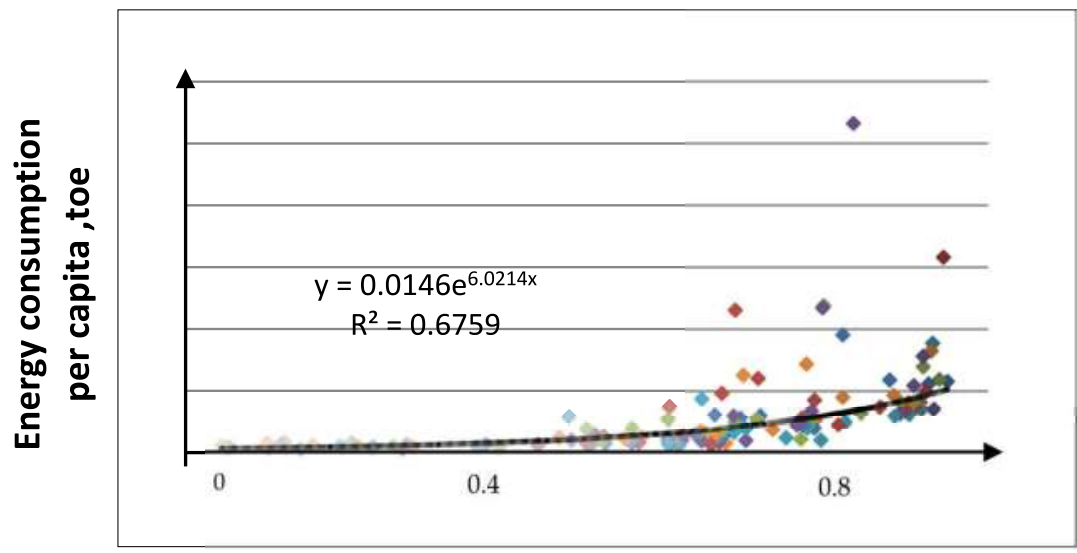

\section{HDI}

Fig. 7. Energy consumption per capita and the HDI (2007).

modern energy, electrification and creation of essential infrastrucuture are more likely to achieve improvement in HDI. However, global efforts together with inidividual low HDI country efforts might be necessary in order to achieve improvement in human development.

For example, lets consider Australia and Kenya as HHD (HDI $=0.970)$ and MHD (HDI = 0.541) nations in 2007 respectively. It should be noted that in the beginning of the sample, Kenya, which is now largest economy in East Africa, had lower HDI value. However in a less than decade government policies on improving human development with the help of international organizations (for example, UN World Food Programm since 2004 was installing energy-efficient stoves in Kenyan schools) have been relatively successful, although a lot of challeneges still remain. While primary energy sources in Australia are brown and black coal and natural gas, Kenya is largely dependent on biomass (wood), imported crude oil and electricity with respective shares 70 per cent, 21 per cent, and 9 per cent of total energy use (UNEP, 2006). While in Australia, major electricity source is coal, in Kenya major sources of electricity are hydro, geothermal and thermal power (UNEP, 2006). Governments of these two countries face different challenges, namely maintaining already high HDI (Australia) and achieving improvement in HDI (Kenya). In both cases, this would require efficient use of energy resources, but for Australia this would also mean significant climate change mitigation policy constraints. For example, Australia has pledged to reduce its GHG emissions (the primary means of achieving is goal is transitional carbon tax on producers and introduction of a national mandatory emissions trading scheme in 2015) and increase investment in alternative energy such as direct geothermal and wave energy. For Kenya, where $80 \%$ of population depends on biomass as the primary source of energy, the challenges lie in improving electricity generation and distribution, creating essential transmission and distribution infrastructure, reducing the cost of electricity, reducing its dependence on crude oil imports and investing in green energy sources (UNEP, 2006). However, the poverty still remains acute in Kenya due to high income inequality, disproportionate access to essential resources including land, susceptibility to natural disasters such as floods and still inadequate access to basic social services including education (Hendriks, 2010, p.99). 
Since HDI is composed of three elements (longevity as proxied by the life expectancy at birth, education as proxied by the gross enrollment and adult litarcy indeces, standard of living as proxied by the GDP per capita), its improvement or maitenance would require achieving progress in all of them. For instance, achieving higher economic growth is no possible without energy use, but the strategies will be different for HHD, MHD and LHD because of different energy mix, different demographic characteristics and different techological levels (more pollusive in developing nations). Due to existing infrastrucuture faciliting as well as technologies, high HDI countries should take a leadership role on reducing energy consumption, reducing emissions and improving energy efficiency measures that could help fostering replicable models of the good quality life that are based on much lower energy consumption levels.

Potential direction for future research would be analysis of causality between energy consumption and human development. Causal relationship (i.e. lead-lag relationsip) between energy consumption and GDP has been examined in the literature at the countryspecific level, as well as based on the panel data analysis. In summary, the findings of these research efforts are mixed and largely depend on the time period of analysis, energy mix and level of country's economic development. However, current literature gap lies in stydying causality between energy consumption, including different enenrgy sources, and development indicators other than GDP, such as for example Human Development Index.

\section{References}

Atkinson, A.B., 1970. On the measurement of inequality. Journal of Economic Theory, 2, 244-263.

Australian Government, 2011. Strong Growth, Low pollution- modelling a carbon price. Available online at: www.treasury.gov.au/carbonpricemodelling/content/report.asp

Banerjee, A., Yakovenko, V. M., 2010. Universal patterns on inequality, New Journal of Physics, 12, 075032.

Birol, F., 2007. Energy economics: a place for energy poverty in the agenda?. The Energy Journal, 28, 01-06.

Blackorby, C., Donaldson, D., 1978. Measures of relative equality and their meaning in terms of social welfare. Journal of Economic Theory, 18, 59-80.

Brune N., Garrett G., 2005. The globalization Rorschach test: international economic integration, inequality, and the role of government. Annual Review of Political Science, 8, 399-423.

Chakravarty, S.R., 1990. Ethical social index numbers. Springer-Verlag, Heidelberg, New York,London, Paris, Tokyo, Hong Kong.

Champernowne, D.G., Cowell, F.A., 1998. Economic inequality and income distribution. Cambridge Univ. Press, United Kingdom.

Cowell, F.A., 1995. Measuring income inequality (2nd ed.), Harvester Wheatsheaf, Hemel Hempstead.

Dalton, H., 1920. The measurement of the inequality of incomes. Economic Journal, 30, 348361.

Dasgupta, P., Sen, A., Starrett, D., 1973. Notes on the measurement of inequality. Journal of Economic Theory, 6, 180-187. 
Druckman A, Jackson T., 2008. Measuring resource inequalities: the concepts and methodology for an area-based Gini coefficient. Ecological Economics, 65, 242-52.

Duro, J.A., Padilla, E., 2006. International inequalities in per capita $\mathrm{CO}_{2}$ emissions: a decomposition methodology by Kaya factors. Energy Economics, 28, 170-187.

Foster, J.E., 1985. Inequality measurement. Proceedings of Symposia in Applied Mathematics, 33, 31-68.

Foster, J.E., Shorrocks, A.F., 1988. Inequality and poverty orderings. European Economic Review, 32, 654-662.

Giannini Pereira, M., Vasconcelos Freitas, M. A., Fidelis da Silva, N., 2011. The challenge of energy poverty: Brazilian case study. Energy Policy, 39, 167-175.

Groot L., 2010. Carbon Lorenz curves. Resource and Energy Economics, 32, 45-64.

Hedenus, F., Azar , C., 2005. Estimates of trends in global income and resource inequalities. Ecological Economics, 55, 351-364.

Heil, M.T., Wodon, Q.T., 1997. Inequality in $\mathrm{CO}_{2}$ emissions between poor and rich countries. Journal of Environment and Development, 6, 426-452.

Heil, M.T., Wodon ,Q.T., 2000, Future inequality in $\mathrm{CO}_{2}$ emissions and the impact of abatement proposals. Environmental and Resource Economics, 17, 163-181.

Hendriks, B., 2010, Urban livelihoods, institutions and inclusive governance in Nairobi. 'Spaces' and their impacts on quality of life, influence and political rights. Amsterdam University Press.

International Energy Agency (IEA), 2011. Access to electricity. Available online at: http://www.iea.org/weo/electricity.asp

Jacobson, A., Milman, A. D., Kammen, D. M., 2005. Letting the (energy) Gini out of the bottle: Lorenz curves of cumulative electricity consumption and Gini coefficients as metrics of energy distribution and equity. Energy Policy, 33, 1825-1832.

Jacmart, M. C., Arditi, M., Arditi, I., 1979. The world distribution of commercial energy consumption. Energy Policy, 7, 199-207.

Kolm, S.-C., 1976a. Unequal inequalities I. Journal of Economic Theory, 12, 416-442.

Kolm, S.-C., 1976b. Unequal inequalities II. Journal of Economic Theory, 13, 82-111.

Lambert, P.J., 1993. The Distribution and redistribution of income: a mathematical analysis. Manchester Univ. Press, Manchester and New York.

Moriarty, P., Honney, D., 2010. A Human needs approach to reducing atmospheric carbon. Energy Policy, 38, 695-700.

Opschoor, H., 2009. Sustainable development and a dwindling carbon space. Environmental and Resources Economics, DOI 10.1007/s10640-009-9332-2.

Pachauri, S., Spreng, D., 2003. Energy use and energy access in relation to poverty. Centre for Energy Policy and Economics-Swiss Federal Institutes of Technology, Working Paper No. 25, Zurich, Switserland.

Padilla, E., Serrano, A., 2006. Inequality in $\mathrm{CO}_{2}$ emissions across countries and its relationship with income inequality: a distributive approach. Energy Policy, 34, 1762-1772.

Pasternak, A. D., 2000. Global energy futures and human development: a framework for analysis. US Department of Energy Report UCRL-ID- 140773, Lawrence Livermore National Laboratory, Livermore, CA.

Rosas-Flores, J.A., Galvez, D. M., 2010. What goes up: Recent trends in Mexican residential energy use. Energy, 35, 2596-2602. 
Rothschild, M., Stiglitz, J.E., 1973. Some further results on the measurement of inequality. Journal of Economic Theory, 6, 188-204.

Sen, A., 1973. On economic inequality. Oxford Univ. Press, Oxford.

Sinn, H.W., 2007. Public policies against global warming. NBER Working Paper No.W13454, CESifo (Center for Economic Studies and Ifo Institute for Economic Research)/ NBER (National Bureau of Economic Research).

Spreng, D., 2005. Distribution of energy consumption and the $2000 \mathrm{~W} /$ capita target. Energy Policy, 33, 1905-1911.

United Nations Development Programme (UNDP)-Human Development Report Office. 1998-2009. “The Human Development Index (HDI)." New York. Available online at: http://hdr.undp.org/ en/statistics/hdi/.

United Nations Environment Project (UNEP), 2006. Kenya: Integrated assessment of the Energy Policy. Nairobi, UNEP. Available online at: www.unep.ch/etb/areas/pdf/Kenya\%20ReportFINAL.pdf 


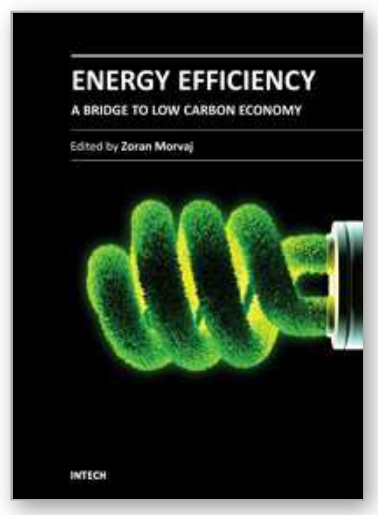

\author{
Energy Efficiency - A Bridge to Low Carbon Economy \\ Edited by Dr. Zoran Morvaj
}

ISBN 978-953-51-0340-0

Hard cover, 344 pages

Publisher InTech

Published online 16, March, 2012

Published in print edition March, 2012

Energy efficiency is finally a common sense term. Nowadays almost everyone knows that using energy more efficiently saves money, reduces the emissions of greenhouse gasses and lowers dependence on imported fossil fuels. We are living in a fossil age at the peak of its strength. Competition for securing resources for fuelling economic development is increasing, price of fuels will increase while availability of would gradually decline. Small nations will be first to suffer if caught unprepared in the midst of the struggle for resources among the large players. Here it is where energy efficiency has a potential to lead toward the natural next step - transition away from imported fossil fuels! Someone said that the only thing more harmful then fossil fuel is fossilized thinking. It is our sincere hope that some of chapters in this book will influence you to take a fresh look at the transition to low carbon economy and the role that energy efficiency can play in that process.

\title{
How to reference
}

In order to correctly reference this scholarly work, feel free to copy and paste the following:

Qiaosheng Wu, Svetlana Maslyuk and Valerie Clulow (2012). Energy Consumption Inequality and Human Development, Energy Efficiency - A Bridge to Low Carbon Economy, Dr. Zoran Morvaj (Ed.), ISBN: 978-95351-0340-0, InTech, Available from: http://www.intechopen.com/books/energy-efficiency-a-bridge-to-lowcarbon-economy/energy-consumption-inequality-and-human-development

\section{INTECH}

open science | open minds

\author{
InTech Europe \\ University Campus STeP Ri \\ Slavka Krautzeka 83/A \\ 51000 Rijeka, Croatia \\ Phone: +385 (51) 770447 \\ Fax: +385 (51) 686166 \\ www.intechopen.com
}

\author{
InTech China \\ Unit 405, Office Block, Hotel Equatorial Shanghai \\ No.65, Yan An Road (West), Shanghai, 200040, China \\ 中国上海市延安西路65号上海国际贵都大饭店办公楼 405 单元 \\ Phone: +86-21-62489820 \\ Fax: +86-21-62489821
}


(C) 2012 The Author(s). Licensee IntechOpen. This is an open access article distributed under the terms of the Creative Commons Attribution 3.0 License, which permits unrestricted use, distribution, and reproduction in any medium, provided the original work is properly cited. 